\title{
Maria nas conferências episcopais da América Latina
}

\author{
Mary at the Episcopal conferences \\ of Latin-America
}

Geraldo Luiz Borges Hackmann

\section{Resumo}

O presente artigo intenta estudar o pensamento mariano presente nos documentos conclusivos das Conferências Gerais do Episcopado LatinoAmericano e do Caribe (CELAM), com a finalidade de fazer uma resenha das ideias sobre a Virgem Maria, Mãe de Deus, presentes nas Conferências do Rio de Janeiro (1955), Medellín (1968), Puebla (1979), Santo Domingo (1992) e Aparecida (2007), motivado pela importância da devoção mariana na piedade popular dos povos latino-americanos e caribenhos.

Palavras-chave: Maria. Igreja. Conferências do CELAM. América Latina. Devoção Mariana.

\section{Abstract}

This article intends to study the Marian thought present in the conclusive documents of the General Conference of the Latin-American and Caribbean Episcopate (CELAM), with the intent of writing a review of the ideas about the Virgin Mary, Mother of God, present in the Conferences of Rio de Janeiro (1955), Medellin (1968), Puebla (1979), Santo Domingo (1992) and Aparecida (2007), motivated by the importance of the Marian devotion in the popular piety of the Latin-American and Caribbean peoples.

Keywords: Mary. Church. CELAM Conferences. Latin-America. Marian devotion. 


\section{Introdução}

A devoção a Nossa Senhora na América Latina sempre teve uma importância muito grande. Ela veio com os colonizadores. E, desde então, os povos latino-americanos guardaram a sua fé e identidade religiosa católica através das práticas de devoção mariana, especialmente o Rosário. Puebla faz esta constatação ao afirmar que "a piedade mariana é com frequência o vínculo resistente que mantém fiéis à Igreja setores que carecem de atenção pastoral adequada". ${ }^{1}$

O Papa João Paulo II intui que Maria pertence à identidade própria dos povos latino-americanos e caracteriza a sua piedade popular, quando afirmava, na visita ao Santuário de Nossa Senhora de Zapopán, México, no dia 30 de janeiro de 1979:

Se isto é verdade em todo o mundo católico, muito mais o é no México e na América Latina. Pode-se dizer que a fé e a devoção a Maria e seus mistérios pertencem à identidade própria destes povos e caracterizam a sua piedade popular, da qual falava o meu predecessor Paulo VI na Exortação Apostólica Evangelii Nuntiandi (Cf. Evangelii Nuntiandi, n. 48). ${ }^{2}$ Esta piedade popular não é por força um sentimento vago, destituído de sólida base doutrinal como se constituísse forma inferior de manifestação religiosa. Quantas vezes é, pelo contrário, como que a expressão verdadeira da alma dum povo, ao ser tocada pela graça e forjada pelo encontro feliz entre a obra de evangelização e a cultura local, de que fala também a Exortação acima citada (Evangelii Nuntiandi, n. 20). Assim, guiada e sustentada, e, se for o caso, purificada pela ação constante dos pastores, e exercida diariamente na vida do povo, a piedade popular é verdadeiramente a piedade dos "pobres e simples" (Evangelii Nuntiandi, n. 48). É a maneira como estes prediletos do Senhor vivem e traduzem, nas suas atitudes humanas e em todas as dimensões da vida, o mistério da fé que receberam.

Esta piedade popular no México e em toda a América Latina é forçosamente mariana. Nela, Maria Santíssima ocupa o mesmo lugar preeminente que ocupa na totalidade da fé cristã. Ela é a mãe, a rainha, a protetora e o

\footnotetext{
${ }^{1}$ CONSELHO EPISCOPAL LATINO-AMERICANO. Puebla. A evangelização no presente $e$ no futuro da América Latina. $3^{\text {a }}$ Conferência. Petrópolis: Vozes, 1979, n. 284. Daqui em diante, será citado como Puebla.

${ }^{2}$ PAPA PAULO VI. Exortação Apostólica Evangelii Nuntiandi, de 08 de dezembro de 1975. In: ACTA APOSTOLICAE SEDIS 68 (1975), pp. 5-76.
} 
modelo. A ela se vem para honrá-la, para pedir a sua intercessão, para aprender a imitá-la, quer dizer, para aprender a ser verdadeiro discípulo de Jesus. Porque, como o mesmo Senhor diz: Quem fizer a vontade de Deus é meu irmão, minha irmã e minha mãe $(M c 3,35)$.

Longe de ocultar a mediação insubstituível e única de Cristo, esta função de Maria sendo acolhida e posta em relevo, "serve para demonstrar o poder d'Ela", como ensina o Concílio Vaticano II (Lumen Gentium, n. 60), ${ }^{3}$ porque tudo o que ela é e tem, vem-lhe da "superabundância dos méritos de Cristo, apoia-se na sua mediação" e a ele conduz (Lumen Gentium, n. 60). Os fiéis que vêm a este santuário bem o sabem e põem-no em prática, ao dizerem — sempre com ela, olhando para Deus Pai, no dom do seu Filho amado tornado presente entre nós pelo Espírito - : Glorifica a minha alma ao Senhor $(L c 1,46){ }^{4}$

A seguir, estudar-se-á a presença de Maria nas diversas Conferências Gerais do Episcopado da América Latina e do Caribe, seguindo a ordem cronológica.

\section{No Rio de Janeiro e em Medellín, Maria é apenas invocada}

A primeira Conferência Geral do CELAM, realizada no Rio de Janeiro, de 25 de julho a 04 de agosto de 1955, e que deu origem ao Conselho Episcopal Latino-Americano (CELAM), ${ }^{5}$ cita apenas duas vezes Nossa Senhora, a mãe

${ }^{3}$ CONCÍLIO ECUMÊNICO VATICANO II. Constituição dogmática Lumen Gentium, de 21 de
novembro de 1964 . In: ACTA APOSTOLICAE SEDIS 57 (1965), pp. 5-67.
${ }^{4}$ PAPA JOÃO PAULO II. Discurso no Santuário de Nossa Senhora de Zapopán, n. 2. In: ACTA
APOSTOLICAE SEDIS, LXXI (1979), p. 228 .
${ }^{5}$ A primeira Conferência Geral do Episcopado da América latina foi convocada por iniciativa
direta da Santa Sé. A Conferência Nacional dos Bispos do Brasil (CNBB), que havia sido criada
em 1952 , foi encarregada de auxiliar na preparação. O Papa Pio XII enviou uma carta para ser
lida na abertura da Conferência, intitulada Ad Ecclesiam Christi, e que serviu de orientação para
os trabalhos realizados. Participaram das sessões de trabalho no Colégio Sacré Coeur os car-
deais latino-americanos, exceto os dois da Argentina, 37 arcebispos e 58 bispos, que representa-
vam 66 arquidioceses, 218 dioceses, 33 prelazias, 43 vicariatos e 15 prefeituras apostólicas. No
total, a Assembleia esteve composta de representantes diretos de 23 países, 60 províncias, 350
circunscrições eclesiásticas e 150 milhões de católicos. Presidiu a Conferência como legado
pontifício, o Cardeal Adeodato Giovanni Piazza, secretário da Sagrada Congregação Consisto-
rial, auxiliado por Dom Antônio Samoré, secretário da Congregação para Assuntos Eclesiásti-
cos Extraordinários. Os Bispos debateram o problema da escassez de vocações sacerdotais, a
instrução religiosa, a condição social e material dos povos do Continente.
No final da Conferência, os bispos pediram ao Papa Pio XII a criação de um organismo que 
de Deus. A primeira é na Mensagem e a segunda quando se recomenda o respeito e o incremento da piedade popular, na qual se insere a devoção mariana. ${ }^{6}$

A conferência de Medellín foi celebrada do dia 24 de agosto até o dia 06 de setembro de 1968, na cidade de Medellín, Colômbia. Seu objetivo particular foi fazer a aplicação do Concílio Vaticano II para a América Latina. Por isso, Segundo Galilea considera que Medellín foi não somente a aplicação do Concílio Ecumênico Vaticano II para a América Latina, mas a sua "aplicação criativa". ${ }^{7}$ Isso significa que os bispos reunidos em Conferência não se restringiram em determinar como deveriam ser aplicados os documentos do Concílio Vaticano II na América Latina, mas foram além ao relê-los à luz da realidade do continente, de acordo com o "espírito do Concílio", ${ }^{8}$ e decidir quais eram as atividades pastorais urgentes que dariam resposta eclesial e pastoral aos desafios que a Igreja da América Latina enfrentava naquele momento histórico. Desse modo, o documento final da segunda Conferência tem uma estrutura semelhante aos documentos do Vaticano II. Coincide o mesmo número de documentos: dezesseis. Embora, diferentemente do que os documentos do Vaticano II, os dezesseis documentos de Medellín estão reunidos em três eixos chaves: (1) promoção humana, (2) evangelização e crescimento na fé e (3) Igreja visível e suas estruturas. Em torno destes três eixos estão desenvolvidos os dezesseis documentos. ${ }^{9}$

congregasse o episcopado das nações do Continente e unisse as suas forças. O pedido foi aprovado no dia 02 de novembro de 1955, quando foi criado oficialmente o Conselho Episcopal Latino-Americano (CELAM), com sede em Bogotá, na Colômbia.

${ }^{6}$ CONSELHO EPISCOPAL LATINO-AMERICANO. "Rio de Janeiro (1955). I I Conferencia General del CELAM". Disponível em: <http://www.cpalsj.org/wp-content/uploads/2013/03/ Documento_Conclusivo_Rio1.pdf $>$. Acesso em 27 de junho de 2017.

${ }^{7}$ É assim que o autor expressa a sua conclusão ao intitular deste modo o seu artigo: GALILEA, S. "L'America Latina nelle conferenze di Medellín e Puebla. Um esempio di ricezione seletiva e creativa del concilio". In: ALEBERIGO, G.; JOSSUA, J.-P. Il Vaticano II e la Chiesa. Brescia: Paideia, 1985, pp. 87-106.

${ }^{8}$ Alberigo entende pela expressão "espírito do Concílio" levar em conta não apenas o corpus conciliar, ou seja, os documentos, mas a atmosfera complexiva de tudo o que envolveu o Concílio como evento antes e depois de sua realização: ALBERIGO, G. "Fedeltà e criatività nella ricezione del Concilio Vaticano II. Criteri ermeneutici”. In: ALBERIGO, G. Transizione epocale. Studi sul Concilio Vaticano II. Bologna: Il Mulino, 2009, p. 59.

${ }^{9}$ Do primeiro eixo são cinco documentos: Justiça, Paz, Família e demografia, Educação e Juventude. Do segundo eixo são os quatro documentos: Pastoral popular, Pastoral de Elites, Catequese e Liturgia. Do terceiro eixo são sete documentos: Movimento de Leigos, Sacerdotes, Religiosos, Formação do Clero, Pobreza da Igreja, Pastoral de Conjunto e Meios de Comu- 
Sendo assim, a Conferência de Medellín foi marcada por uma circunstância histórica bem configurada. A atenção dos bispos estava centrada no desafio que a situação social, política e econômica do Continente trazia para a Igreja latino-americana, que, segundo eles, não poderia ficar indiferente aos sofrimentos dos povos onde a Igreja anunciava a Boa Nova do Reino de Deus. Silvia Scatena, ao escrever sobre a trajetória da Igreja latino-americana do Concílio Vaticano II à Medellín, aponta três palavras com as quais descreve a feição assumida pela Igreja do continente: pobre, missionária e pascal. ${ }^{10}$

Especificamente sobre o tema aqui estudado, o documento de Medellín não dá espaço relevante à Maria, ${ }^{11}$ a Mãe de Deus, citando-a apenas em dois momentos diferentes, pois tinha preocupação pastoral e não problemas teológicos para resolver. O primeiro momento é no final da Mensagem aos povos da América Latina, publicada no dia 06 de setembro de 1968, com as seguintes palavras: "Colocamos sob a proteção de Maria, a mãe da Igreja e padroeira da América latina, todo o nosso trabalho e esta mesma esperança, a fim de que se antecipe o Reino de Deus". ${ }^{12}$ O segundo momento é na Introdução às Conclusões, no número 8:

Em torno de Maria, Mãe da Igreja, que com seu patrocínio assiste a este Continente desde sua primeira evangelização, imploramos as luzes do Espírito Santo e, perseverando em oração, alimentamo-nos do pão da Palavra e da Eucaristia (Medellín, p. 43).

Percebe-se que em ambas as citações Maria é invocada como a mãe da Igreja. Este título entrou na veneração oficial da Igreja a partir da proclamação da maternidade de Maria para com toda a Igreja feita pelo Papa Paulo VI, no dia 21 de novembro de $1964,{ }^{13}$ no discurso de encerramento da terceira sessão

\footnotetext{
nicação Social. Os títulos dos documentos já dão uma ideia das preocupações dos bispos e o que determinou a atenção dos mesmos quando refletiram sobre a resposta a dar aos desafios enfrentados pela Igreja na década de sessenta do século passado.

${ }^{10}$ SCATENA, S. In populo pauperum. La Chiesa latino-americana dal Concilio a Medellín (1962-1968). Bologna: Il Mulino, 2007, p. 511.

${ }^{11}$ É também a opinião de FASSINI MS, A. "Maria na pastoral latino-americana". Convergência 153 (1982), pp. 268-269.

${ }^{12}$ CONSELHO EPISCOPAL LATINO-AMERICANO (CELAM). A Igreja na atual transformação da América Latina à luz do Concílio. Conclusões de Medellín. Petrópolis: Vozes, 1977, p. 40 (daqui em diante Medellin).

${ }^{13} \mathrm{O}$ texto da proclamação é o seguinte: "Portanto, para glória da Virgem e para nosso conforto, proclamamos Maria Santíssima 'Mãe da Igreja', isto é, de todo o Povo de Deus, tanto dos fiéis
} 
do Vaticano II, e presente no último capítulo da Constituição dogmática Lumen Gentium, no número 63. Este título é um desdobramento do dogma da maternidade divina de Maria, a primeira e central verdade doutrinal mariana proclamada solenemente pela Igreja no Concílio de Éfeso, no ano de 431. Esse dogma afirma que ela não foi apenas mãe da humanidade de Jesus Cristo, contra o reducionismo nestoriano, mas que o filho que ela gerou em seu seio era verdadeiramente uma única pessoa, divino e humano ao mesmo tempo, e, por isso, ela pode ser proclamada mãe de Deus. ${ }^{14}$

A intenção do Papa Paulo VI ao proclamar Maria como mãe da Igreja foi destacar o papel maternal que Maria exerce sobre toda a Igreja:

A reflexão sobre estas estreitas relações de Maria com a Igreja, tão claramente estabelecidas pela atual Constituição conciliar, faz-Nos pensar ser este o momento mais solene e mais apropriado para satisfazermos um desejo que, por Nós acenado no fim da sessão precedente, muitíssimos Padres conciliares fizeram seu, pedindo instantemente uma declaração explícita, durante este Concílio, da função maternal que a Virgem exerce sobre o povo cristão. Para tal fim, julgamos oportuno consagrar, nesta mesma sessão pública, um título em honra da Virgem, sugerido de várias partes do orbe católico e a Nós particularmente caro, porque em síntese admirável exprime o lugar privilegiado que este Concílio reconhece à Virgem na santa Igreja.

Efetivamente, assim como a maternidade divina é o fundamento da especial relação de Maria com Cristo e da sua presença na economia da salvação operada por Jesus Cristo, assim também constitui essa maternidade o fundamento principal das relações de Maria com a Igreja, sendo Ela Mãe daquele que, desde o primeiro instante da Sua Encarnação no seu seio virginal, uniu a si, como Cabeça, o seu Corpo místico, que é a Igreja. Maria, pois como Mãe de Cristo, também é Mãe dos fiéis e dos pastores todos, isto é, da Igreja. ${ }^{15}$

como dos pastores, que lhe chamam Mãe amorosíssima; e queremos que com este título suavíssimo seja a Virgem doravante honrada e invocada por todo o povo cristão" (PAPA PAULO VI. Discurso de Clausura da Terceira Sessão do Concílio Ecumênico Vaticano II, em 21 de novembro de 1964. In: ACTA APOSTOLICAE SEDIS 56 (1964), pp. 1007-1018).

${ }^{14}$ Cf. DENZINGER, H.; HÜENERMANN, P. Compêndio dos símbolos, definições e declarações de fé e moral. São Paulo: Paulinas e Loyola, 2007, n. 251.

${ }^{15}$ PAPA PAULO VI. Discurso de conclusão da terceira sessão do Concílio Ecumênico Vaticano II, em 21 de novembro de 1964. In: ACTA APOSTOLICAE SEDIS 56 (1964), pp. 1007-1018. 


\section{Em Puebla, Maria é a estrela da evangelização e mãe e modelo para os povos da América Latina}

A terceira Conferência Geral do Episcopado Latino-americano aconteceu na cidade de Puebla de los Angeles, no México, de 27 de janeiro a 13 de fevereiro de 1979, e teve como tema central $A$ evangelização no presente e no futuro da América Latina. O tema abordado dá um lugar central para a Exortação Pós-sinodal do Papa Paulo VI, a Evangelii Nuntiandi.

A escolha do tema mostra um novo momento eclesial vivido pela Igreja universal: após a crise que se sucedeu os primeiros anos do término do Vaticano II, ${ }^{16}$ já transcorrida uma década, o Papa Paulo VI convocou a III Assembleia Geral ordinária do Sínodo dos Bispos, em Roma, que aconteceu de 27 de setembro a 26 de outubro de 1974, para refletir sobre $A$ evangelização no mundo contemporâneo, que resultou na publicação da Exortação Apostólica Evangelii Nuntiandi, publicada em 08 de dezembro de 1975. Fiel a esse novo momento eclesial, a nova Conferência do CELAM decide também refletir sobre a evangelização, procurando aplicar a Exortação do Papa Paulo VI para a América Latina. Neste sentido, não há uma mudança do rumo iniciado em Medellín. Há, sim, a inclusão de uma nova perspectiva ao movimento pastoral começado em 1968: a Igreja da América Latina também passa a centrar a sua reflexão e ação pastoral em torno da evangelização, embora trazendo a sua contribuição específica. Aqui vem unido o tema da evangelização ao da libertação: eis a especificidade da contribuição da Igreja latino-americana à reflexão eclesial. ${ }^{17}$ Desse modo, fica assegurada a continuidade entre as duas Conferências.

Diferentemente da Conferência anterior, Puebla dedica uma parte significativa de seu documento final à Nossa Senhora. ${ }^{18}$ Ela se encontra na

\footnotetext{
${ }^{16}$ Muitos pensadores afirmam que a causa fundamental da crise pós-conciliar foi provocada devido a uma falta de compreensão da identidade da Igreja e não provocada pelo Vaticano II, como, por vezes, se afirmava.

${ }^{17}$ Convém lembrar que a teologia da libertação foi tomando corpo na América Latina e ganhando força cada vez maior. Isto também foi auxiliado pela mudança da situação política na América Latina de modo geral: os governos militares fora enfraquecendo e o movimento pela redemocratização foi crescendo. Da parte eclesial, várias iniciativas foram tomadas a partir de Medellín, que foram moldando uma nova pastoral de conjunto em diversos países da América Latina.

${ }^{18}$ CONFERÊNCIA GERAL DO EPISCOPADO LATINO-AMERICANO. Puebla. A evangelização no presente e no futuro da América Latina. $3^{\text {a }}$ Conferência. Petrópolis: Vozes, 1979.
} 
segunda parte do documento, intitulada Desígnios de Deus sobre a realidade da América Latina, quando, no primeiro capítulo, intitulado Conteúdo da evangelização, encontram-se as conhecidas três verdades: "a verdade a respeito de Jesus Cristo, o Salvador que anunciamos" (Puebla n. 1), "a verdade a respeito da Igreja: o Povo de Deus, sinal e serviço de comunhão" (Puebla n. 2) e "a verdade a respeito do homem: a dignidade humana" (Puebla n. 3). A exposição da mariologia de Puebla encontra-se na verdade a respeito da Igreja, no ponto 2.4, intitulado Maria, mãe e modelo da Igreja, do número 282 a 303. A exposição do conteúdo do texto aborda dois aspectos fundamentais: Maria como mãe da Igreja e como modelo da Igreja. Destarte, a mariologia de Puebla não está isolada, mas faz parte integrante da Igreja que está na América Latina: parte de Jesus Cristo para chegar aos homens e mulheres da América Latina, onde ela surge como modelo eminente da Igreja, por isso, mãe e modelo da Igreja. ${ }^{19}$

Previamente, é necessário fazer uma observação para compreender a importância da devoção a Maria na Igreja latino-americana: seguindo o Papa Paulo VI, ${ }^{20}$ o documento afirma que a devoção mariana é elemento "qualificador" e "intrínseco" da "genuína piedade da Igreja" e "do culto cristão", porque "sabe o povo que encontra Maria na Igreja Católica", e constata, como já referido anteriormente, que "a piedade mariana é com frequência o vínculo resistente que mantém fiéis à Igreja setores que carecem de atenção pastoral adequada" (Puebla n. 284). Os bispos reconhecem que a devoção mariana propiciou aos setores do Continente sem atendimento pastoral direto manterem a sua fé e continuarem ligados à Igreja Católica. Esta afirmação tem um sentido profundo, pois afirma a devoção mariana como responsável pela permanência das comunidades latino-americanas sem assistência religiosa sistemática fiéis à fé em Jesus Cristo. Eis a importância da piedade popular vivida pelos povos latino-americanos.

O primeiro aspecto abordado pelo documento é a maternidade de Maria em relação com a Igreja. O documento de Puebla a entende a partir de alguns aspectos, a saber: a sua fecundidade maravilhosa para com a Igreja por ter cooperado com o amor salvífico de Deus para com a humanidade, o que a torna mãe de toda a humanidade; ela se realiza na ordem da graça por ter cooperado com seu Filho Jesus Cristo, do qual "nascia a família dos redimidos"; por

\footnotetext{
${ }^{19}$ Cf. FASSINI MS, A. “Maria na pastoral latino-americana”. Convergência 153 (1982), p. 273. ${ }^{20}$ Cf. PAPA PAULO VI. Exortação Apostólica Marialis Cultus, de 02 de fevereiro de 1974. In: ACTA APOSTOLICAE SEDIS 46 (1974), n. 56.
} 
ter implorado o Espírito Santo vivificador sobre a Igreja em Pentecostes, na qual irrompe a vitoriosa vida de Cristo; por ela estar presente no processo de evangelização, entendido como "transformar a partir de dentro", entendido, desse modo, como um parto, no qual ela, como mãe, cuida dos filhos e irmãos de Cristo que ainda peregrinam (cf. Lumen Gentium, n. 62) para que "tenham vida abundante e cheguem à maturidade da plenitude de Cristo" (Puebla n. 288); por ela velar e interceder por todos os povos e não apenas pela Igreja, pois ela "tem um coração tão grande quanto o mundo"; por ela cuidar para que o Evangelho "penetre intimamente, plasme a vida de cada dia" e "produza frutos de santidade" nos cristãos e, assim, "precisa ser cada vez mais a pedagoga do Evangelho na América Latina" (Puebla n. 290), como "mãe educadora da fé" (cf. Lumen Gentium, n. 63). E conclui este ponto desta forma:

Maria é verdadeiramente mãe da Igreja. Paulo VI faz sua uma fórmula concisa da tradição: "Não se pode falar da Igreja sem que esteja presente Maria" (Marialis Cultus 28). Trata-se de uma presença feminina, que cria o ambiente de família, o desejo de acolhimento, o amor e o respeito à vida. É presença sacramental dos traços maternais de Deus. É uma realidade tão profundamente humana e santa que desperta nos crentes as preces da ternura, da dor e da esperança (Puebla n. 291).

O documento aborda um segundo aspecto: Maria é modelo da Igreja. A fundamentação para compreendê-la desta maneira é que ela é modelo em sua relação com Cristo: "Segundo o plano de Deus, em Maria, "tudo se refere a Cristo e tudo depende dele'(Marialis Cultus, n. 25). Toda a sua existência é uma plena comunhão com seu Filho" (Puebla n. 292). Isto se deu na vida de Maria graças à sua maternidade, que foi o evento determinante para todo o restante de sua vida, iniciado na anunciação (cf. $L c$ 1,26-38). Pela maternidade, Maria fez de si uma entrega generosa e total a Deus, "cheia de lucidez e permanente, unida a uma história de amor a Cristo íntima e santa, uma história única que culmina na glória" (Puebla n. 292). Por isso, ela se torna colaboradora da obra de seu Filho. É o que a tradição da Igreja denomina de "corredentora":

Ela não é apenas o fruto admirável da redenção; é também sua cooperadora ativa. Em Maria se manifesta preclaramente que Cristo não anula a criatividade dos que a seguem. Ela, associada a Cristo, desenvolve todas as suas capacidades e responsabilidades humanas, até chegar a ser a nova Eva juntamente com o novo Adão (Puebla n. 293). 
Mais tarde, o Papa João Paulo II irá citar na terceira parte da Encíclica Redemptoris Mater, do n. 38 ao 41, este elemento da tradição mariana da Igreja. ${ }^{21}$ Daí cresce cada vez mais a consciência de que a importância de Maria para a Igreja decorre de sua maternidade divina. ${ }^{22}$

Outro aspecto da compreensão de Maria como modelo para a Igreja é associá-la a todas as pessoas humanas. O documento afirma que no momento em que "nossa Igreja Latino-americana que dar um novo passo de fidelidade ao Senhor", é necessário olhar para a "figura viva de Maria", pois ela ensina que a "virgindade é uma entrega exclusiva a Jesus Cristo, em que a fé, a pobreza e a obediência ao Senhor se tornam fecundas pela ação do Espírito Santo", porque a "virgindade materna de Maria conjuga, no mistério da Igreja, essas duas realidades: toda de Cristo e, com Ele, toda servidora dos homens" (Puebla n. 294). Ela é modelo de todos os fiéis porque ela "desperta o coração do filho adormecido em cada homem", na medida em que ajuda a cada pessoa a desenvolver a vida batismal e a crescer na fraternidade e, assim, "Maria faz com que a Igreja se sinta uma família" (Puebla n. 295).

Além disso, ela é modelo extraordinário para a Igreja na ordem da fé (cf. $M c$ 3,31-34), pois ela crê, e a fé resplandece nela como "dom, abertura, resposta e fidelidade", e que a faz discípula perfeita, por sua abertura à Palavra de Deus e por se deixar moldar por seu dinamismo, meditando a Palavra e conservando-a no coração quando não a entende e se surpreender (cf. $L c$ 2,51),

\footnotetext{
21 "A Igreja sabe e ensina que 'todo o influxo salutar da Santíssima Virgem em favor dos homens se deve ao beneplácito divino e ... dimana da superabundância dos méritos de Cristo, funda-se na sua mediação, dela depende absolutamente, haurindo aí toda a sua eficácia; de modo que não impede o contato imediato dos fiéis com Cristo, antes o facilita'. Este influxo salutar é apoiado pelo Espírito Santo, que, assim como estendeu a sua sombra sobre a Virgem Maria, dando na sua pessoa início à maternidade divina, assim também continuamente sustenta a sua solicitude para com os irmãos do seu Filho. Efetivamente, a mediação de Maria está intimamente ligada à sua maternidade e possui um carácter especificamente maternal, que a distingue da mediação das outras criaturas que, de diferentes modos e sempre subordinados, participam na única mediação de Cristo; também a mediação de Maria permanece subordinada. Se, na realidade, 'nenhuma criatura pode jamais colocar-se no mesmo plano que o Verbo Incarnado e Redentor', também é verdade que 'a mediação única do Redentor não exclui, antes suscita nas criaturas uma cooperação multiforme, participada duma única fonte'; e assim, 'a bondade de Deus, única, difunde-se realmente, de diferentes modos, nas criaturas"' (PAPA JOÃO PAULO II. Carta Encíclica Redemptoris Mater, de 25 de março de 1987. In: ACTA APOSTOLICAE SEDIS 79 (1987), n. 38).

${ }^{22}$ Cf. MÜLLER. A. "La posizione e la cooperazione di Maria nell'evento di Cristo". In: FEINER, J.; LÖHRER, M. Mysterium Salutis. Nuovo corso di dogmatica come teologia dela storia dela salvezza. Vol. 6. Brescia: Queriniana, 1973, p. 515.
} 
assim como persistindo nela mesmo quando lhe pareça dura aos ouvidos (cf. $J o$ 2,4). Fé que a associa à cruz, na morte de seu Filho, e que a faz "virgem fiel em quem se cumpre a bem-aventurança maior: 'feliz aquela que acreditou' ( $L c$ 1,45)" (Puebla n. 296).

O cântico do Magnificat é apresentado como "espelho da alma de Maria", pois neste poema ela se "manifesta vazia de si própria e depositando toda a sua confiança na misericórdia do Pai" (Puebla n. 297). Além disso, ela se apresenta como modelo, como assevera o Papa João Paulo II na homilia de Zapopán: "para os que não aceitam passivamente as circunstâncias adversas da vida pessoal e social, nem são vítimas da alienação, como se diz hoje, mas que proclamam com ela que Deus 'exalta os humildes', e se for o caso, 'derruba os poderosos de seus tronos". ${ }^{23}$

O documento ainda apresenta mais dois aspectos: modelo de mulher e de serviço eclesial na América Latina. Ao recordar os dogmas marianos, o documento conclusivo de Puebla afirma que Maria apresenta o "rosto do homem novo redimido" em um "Continente onde a profanação do homem é uma constante e onde muitos se fecham num fatalismo passivo" (Puebla n. 298). Por isso, também, ela é modelo de mulher, o que adquire importância maior em um Continente "em que a mulher deve ser valorizada muito mais e em que as suas tarefas sociais se estão definindo com mais clareza e amplidão" (Puebla n. 299). Percebe-se aqui a preocupação dos Bispos em Puebla de valorizar a mulher e resgatar seu papel social, o que ela desempenha sem ser reconhecida. ${ }^{24} \mathrm{O}$ mesmo se encontra no ponto dedicado à missão da mulher na Igreja, que apresenta Maria como modelo de desempenho da missão da mulher na Igreja (cf. Puebla n. 844).

Ela se torna, também, modelo de serviço eclesial na América Latina por ela se ter feito serva do Senhor, como a apresenta a Sagrada Escritura em diversos textos, como o da Anunciação, o do Magnificat e o das bodas de Caná. A respeito, conclui o documento: "Todo o serviço que Maria presta aos homens consiste em abri-los ao Evangelho e convidá-los a obedecer-lhe; 'Fazei o que ele vos disser' ( $\left.J_{o} 2,5\right)$ )" (Puebla n. 300). Ainda há uma afirmação

\footnotetext{
${ }^{23}$ PAPA JOÃO PAULO II. "Discurso no Santuário de Nossa Senhora de Zapopán”, n. 2. In: ACTA APOSTOLICAE SEDIS, LXXI (1979), p. 230.

${ }^{24}$ A propósito, o Papa João Paulo II escreveu uma Carta para as mulheres, sobre a sua dignidade e vocação, intitulada Mulieris Dignitatem e publicada em 15 de agosto de 1988 (PAPA JOÃO PAULO II. Carta Mulieris Dignitatem, de 15 de agosto de 1988. In: ACTA APOSTOLICAE SEDIS 80 (1988), pp. 1653-1729).
} 
interessante: devido ao evento da encarnação, ela se torna o ponto de união entre o céu e a terra, pois "sem Maria desencarna-se o Evangelho, desfigura-se e transforma-se em ideologia, em racionalismo espiritualista" (Puebla n. 302).

Por fim, o documento afirma que o povo latino-americano conhece bem tudo isso e sabe que o importante é evangelizar de forma profunda e não de forma decorativa ${ }^{25}$ por isso, com "nova lucidez e nova decisão", a Igreja da América Latina deseja evangelizar na raiz da cultura do povo e, para tal, voltase para Maria "para que o Evangelho se torne mais carne, mais coração na América Latina" (Puebla n. 303).

Já no Discurso inaugural da Conferência, no dia 28 de janeiro de 1979, o Papa João Paulo II invocava a proteção de Maria, a Mãe de Deus, para as pessoas e os trabalhos a serem realizados durante os dias da Conferência e lembrou que ela se desenvolveria sob a presença espiritual de Nossa Senhora de Guadalupe, venerada como Mãe da Igreja na América Latina, pois ela é a "estrela da Evangelização", como afirma o Papa Paulo VI no título do número 82 da Evangelii Nuntiandi.

\section{Em Santo Domingo, Maria é a estrela da nova evangelização}

A IV Conferência do Episcopado Latino-Americano, realizada na cidade de Santo Domingo, na República Dominicana, ${ }^{26}$ foi celebrada para comemorar os 500 anos de evangelização do Continente. Por isso foi escolhido este local, que é o berço da evangelização da América Latina. ${ }^{27}$ Um dado importante para compreender esta Conferência são as visitas do Papa João Paulo II aos diversos países do Continente, quando falava da necessidade de uma nova evangelização para o Continente, por causa da perda crescente de fiéis. Tudo isto deu uma configuração própria para o documento final da Conferência, que aborda três temas centrais, na sua segunda parte, inspirado no discurso do Papa João Paulo II na inauguração

\footnotetext{
${ }^{25}$ A propósito, o documento cita o número 20 da Exortação Pós-Sinodal Evangelii Nuntiandi, do Papa Paulo VI.

${ }^{26}$ CONSELHO EPISCOPAL LATINO-AMERICANO. Conclusões da IV Conferência do Episcopado Latino-Americano. Santo Domingo. Texto oficial. São Paulo: Paulinas, 1992.

${ }^{27}$ O Irmão Nery, como membro da Ameríndia, opina que havia conflitos no interior da Igreja no período da Conferência que prejudicaram o curso dos trabalhos, particularmente por causa da tensão entre a Cúria Romana e a teologia da libertação e de algumas ações pastorais iniciadas em Medellín e continuadas em Puebla: IRMÃO NERY, FSC. Como vi e vivi Santo Domingo. Um diário. Petrópolis: Vozes, 1993.
} 
da Conferência: nova evangelização, promoção humana e cultura cristã. A primeira parte do documento é intitulada Jesus Cristo, evangelho do Pai, e é como se fosse uma introdução ao documento, onde se encontram a profissão de fé e a memória dos 500 anos da primeira evangelização do Continente; a segunda parte, intitulada Jesus Cristo, evangelizador vivo em sua Igreja, é composta por três capítulos: a nova evangelização, a promoção humana e a cultura cristã; e na terceira parte, intitulada Jesus Cristo, vida e esperança da América Latina e do Caribe, estão afirmadas as linhas pastorais prioritárias para o Continente.

A presença de Maria no documento conclusivo de Santo Domingo se dá de diversas formas ao longo do texto final. Todavia, pode-se perceber que ela é invocada como a "estrela da nova evangelização", expressão que recorda a Exortação Pós-Sinodal do Papa Paulo VI, a Evangelii Nuntiandi, como foi referido acima. É o que acontece na conclusão da Mensagem da IV Conferência aos povos da América Latina e do Caribe:

\begin{abstract}
À Nossa Senhora de Guadalupe, Estrela da Nova Evangelização, confiamos nossos trabalhos. Ela tem caminhada com nossos povos desde o primeiro anúncio de Cristo. A ela suplicamos, hoje, que encha de ardor nossos corações, para proclamarmos, com novos métodos e novas expressões, que Jesus Cristo é o mesmo Ontem, Hoje e Sempre ( $H b$ 13,8) (Santo Domingo n. 48).
\end{abstract}

Os membros da Conferência têm consciência que estão reunidos "como um novo cenáculo, em torno de Maria a mãe de Jesus" (Santo Domingo n. 1), o que os levou a relembrá-la várias vezes na profissão de fé, como, por exemplo, quando recordam a presença dela no cenáculo em Pentecostes (cf. Santo Domingo n. 7), na profissão da fé na encarnação no seio virginal de Maria (cf. Santo Domingo n. 8), e ao confirmar a fé do povo latinoamericano, onde proclamam "que a Virgem Maria, Mãe de Cristo e da Igreja, é a primeira redimida e a primeira crente. Maria, a mulher de fé, foi plenamente evangelizada, é a mais perfeita discípula e evangelizadora (cf. Jo 2,1-12)" (Santo Domingo n. 15). E, por isso, os membros da Conferência declaram que, a exemplo dela, se colocam à escuta da Palavra de Deus para poderem comunicá-la aos povos do América Latina (cf. Santo Domingo n. 31). Na Apresentação do Documento, em novembro de 1992, a Comissão de Presidência da Conferência, assim se refere à Maria: 
Que Maria, Mãe da Igreja e Rainha do nosso Continente, ilumine o caminho que, agora, nossa América empreende até uma Nova Evangelização, a qual se concretize num maior compromisso pela promoção integral do homem e impregne com a luz do Evangelho as culturas dos povos latinoamericanos.

Fundamentalmente, o documento mostra a relação de Maria com a Igreja da América Latina, descrevendo-a de diversas formas. Inicialmente, ela é apresentada como modelo de evangelização da cultura, por ser uma mulher judia aberta à "novidade do Evangelho e está presente nas nossas terras como Mãe comum, tanto dos aborígenes como daqueles que para cá vieram, propiciando desde o princípio a nova síntese cultural que é a América Latina e o Caribe" (Santo Domingo n. 229).

Depois, ela, como virgem e mãe, assumiu um papel importante na evangelização das mulheres, pois "tem feito delas evangelizadoras eficazes, como esposas, mães, religiosas, trabalhadoras, camponesas, profissionais". E justifica esta afirmação porque ela "continuamente lhes inspira [às mulheres] a fortaleza para dar a vida, debruçar-se sobre a dor, resistir e dar esperança quando a vida está mais ameaçada, encontrar alternativas quando os caminhos se fecham, como companheira ativa, livre e animadora da sociedade" (Santo Domingo n. 104).

Há, ainda, duas afirmações contundentes, que reforçam a relação dela com a Igreja: a primeira afirmação recomenda como linha pastoral o cultivo da devoção à Santíssima Virgem, Mãe de Cristo e Mãe da Igreja, como garantia da identidade da Igreja (Santo Domingo n. 143), e, segundo, na busca da santidade pelos membros da comunidade eclesial, a Igreja alcança "na Santíssima Virgem a perfeição em virtude da qual não tem mancha nem ruga" (Santo Domingo n. 32). E o documento justifica esta afirmação devido à santidade vivida por ela, que se torna exemplo para a Igreja viver a santidade, que é, segundo o Papa João Paulo II, a chave do ardor renovado da nova evangelização (cf. Santo Domingo n. 32). Tudo isto faz dela modelo e figura da Igreja: "Maria, a mulher solícita ante a necessidade surgida nas bodas de Caná, é modelo e figura da Igreja ante toda forma de necessidade humana (cf. Jo 2,3ss). À Igreja, assim como a Maria, Jesus recomenda preocupar-se pelo cuidado maternal da humanidade, sobretudo dos que sofrem (cf. Jo 19,2627)" (Santo Domingo n. 163).

O texto conclusivo destaca a importância para os pastores da piedade 
popular para a Igreja na América Latina, pois esta encontra "sua expressão especialmente na devoção à Santíssima Virgem, nas peregrinações aos santuários e nas festas religiosas, iluminadas pela Palavra de Deus" (Santo Domingo n. 53). Daí a importância da promoção de uma catequese que instrua o povo, da qual faz parte o esclarecimento da mediação da Virgem Maria e dos santos (cf. Santo Domingo n. 142).

O Papa João Paulo II, no Discurso inaugural, na última parte, afirma que “acompanha-vos a Mãe de Jesus, a Mãe da Igreja, sua presença entranhável em todos os rincões da América Latina e no coração de seus filhos é garantia do sentido profético e ardor evangélico que deve acompanhar vossos trabalhos", para, em seguida, recordar que ela é, como Mãe do Redentor, tipo e modelo da Igreja, por sua fé (cf. $L c$ 1,45) e por ser portadora de Cristo:

Feliz és tu, América, Igreja da América, portadora de Cristo também, que recebeste o anúncio da salvação e creste "nas coisas que te foram ditas da parte do Senhor!" A fé é a tua ventura, a fonte da tua alegria. Felizes vós, homens e mulheres da América Latina, adultos e jovens, que conheceste o Redentor! Junto com toda a Igreja, e com Maria, podeis dizer que o Senhor "pôs seus olhos na humildade de sua serva" $(L c 1,48)$. Felizes vós, os pobres da terra, porque chegou para vós o Reino de Deus (Santo Domingo n. 31).

\section{Em Aparecida, Maria é discípula e missionária}

A V Conferência do CELAM aconteceu no santuário de Aparecida, de 13 a 31 de maio de 2007, na cidade de Aparecida. ${ }^{28}$ Este local foi escolhido pelo Papa Bento XVI por causa da grande devoção mariana ali existente. E esta nova Conferência, como afirma a introdução do documento de Aparecida, "é novo passo no caminho da Igreja, especialmente a partir do Concílio Ecumênico Vaticano II. Ela dá continuidade e, ao mesmo tempo, recapitula o caminho de fidelidade, renovação e evangelização da Igreja latino-americana a serviço de seus povos", já expressa nas Conferências anteriores (cf. Aparecida n. 9).

Como na Conferência de Puebla, em Aparecida há um ponto dedicado totalmente à Maria, o 6.1.4, intitulado Maria, discípula e missionária. De acordo com o espírito geral do Documento, que considera o cristão católico

\footnotetext{
${ }^{28}$ CONSELHO EPISCOPAL LATINO-AMERICANO. Documento de Aparecida. Texto conclusivo da V Conferência Geral do Episcopado Latino-Americano e do Caribe. Brasília e São Paulo: Edições CNBB, Paulus e Paulinas, 2007.
} 
como discípulo missionário, ela é apresentada como a "discípula mais perfeita do Senhor", por causa "de sua fé (cf. Lc 1,45), de sua obediência à vontade de Deus (cf. $L c$ 1,38), assim como por sua constante meditação da Palavra e das ações de Jesus (cf. Lc 2,19.51)", seguindo a indicação dada em Lumen Gentium, n. 53 (Aparecida n. 266). O desenvolvimento deste ponto mostra, a seguir, as razões apresentadas para compreender Maria como discípula e missionária:

a) "Com ela, providencialmente unida à plenitude dos tempos, chega a cumprimento a esperança dos pobres e o desejo de salvação" (Aparecida n. 267);

b) ela gera a Igreja-família, pois a família humana se reúne em torno dela, que "confere alma e ternura à convivência familiar" (Aparecida n. 268);

c) ela é a grande missionária enquanto "continuadora da missão de seu filho e formadora de missionários", além de ter "trazido o Evangelho à nossa América" e estar próxima das pessoas, como demonstram os acontecimentos de Guadalupe e os "diversos títulos e os santuários espalhados por todo o Continente", fazendo com que os povos latino-americanos sintam que ela pertence a eles e eles a ela (cf. Aparecida n. 269);

d) ela é a imagem acabada e fidelíssima do seguimento de Cristo, quando se quer "enfatizar o discipulado e a missão" em nosso Continente; por isso, é "a sua hora", como frisa o Papa Bento XVI no Discurso inaugural da Conferência: "Maria Santíssima, a Virgem pura e sem mancha, é para nós, escola de fé a nos conduzir e nos fortalecer no caminho que conduz ao encontro com o Criador do céu e da terra destinada". E o Papa acrescenta: "Permaneçam na escola de Maria. Inspirem-se em seus ensinamentos. Procurem acolher e guardar dentro do coração as luzes que ela, por mandato divino, envia a vocês do alto" (Aparecida n. 270);

e) ela nos ensina o primado da palavra de Deus na vida do discípulo missionário, porquanto toda a sua vida está marcada e conduzida pela palavra de Deus (cf. Aparecida n. 271);

f) ela ajuda a manter viva a as atitudes de atenção, serviço, de entrega e de gratuidade que devem distinguir os discípulos de seu Filho 
e ensina a pedagogia para que os pobres se sintam em casa, além de que a sua presença nas comunidades latino-americanas "tem enriquecido e continuará a enriquecer a dimensão materna da Igreja e sua atitude acolhedora, que a convertem em 'casa e escola de comunhão' e em espaço espiritual que prepara para a missão" (Aparecida n. 272).

Outro aspecto importante é o destaque dado à piedade popular no documento. É verdade que desde Medellín se encontram referências a esta particularidade da fé popular dos povos latino-americanos, mas é em Aparecida que recebe um destaque próprio, significando o reconhecimento da afirmação do Papa Bento XVI no discurso inaugural da Conferência: a piedade popular é "o precioso tesouro da Igreja Católica na América Latina". ${ }^{29}$ Por isso, o Documento afirma que a piedade popular "é uma maneira legítima de viver a fé, um modo de se sentir parte da Igreja e uma forma de ser missionário, onde se recolhem as mais profundas vibrações da América Latina" (Aparecida n. 264) e é, como assevera o Papa Bento XVI no discurso inaugural da Conferência, apenas aludido, fruto de "uma síntese entre as culturas e a fé cristã". Ainda mais, a piedade popular é uma forma de reconhecer a ternura e o imenso amor de Deus e reunir os povos ao redor de Jesus Cristo:

Nela veem refletida a mensagem essencial do Evangelho. Nossa Mãe querida, desde o santuário de Guadalupe, faz sentir a seus filhos menores que eles estão na dobra de seu manto. Agora, desde Aparecida, convida-os a lançar as redes ao mundo, para tirar do anonimato aqueles que estão submersos no esquecimento e aproximá-los da luz da fé. Ela, reunindo os filhos, integra nossos povos ao redor de Jesus Cristo (Aparecida n. 265).

\section{Conclusão}

O presente estudo leva a reconhecer o lugar preponderante da devoção mariana na Igreja da América Latina. Ela é responsável pela permanência na fé dos povos latino-americanos não assistidos direta e permanentemente pela pastoral da Igreja, tornando-se, por isso mesmo, um elemento específico de

${ }^{29}$ PAPA BENTO XVI. Discurso na Sessão Inaugural dos trabalhos da V Conferência Geral do Episcopado da América Latina e do Caribe, n. 1 (Citado no número 258 do Documento de Aparecida). 
sua piedade popular e inserindo-se, dessa forma, na piedade religiosa genuína da Igreja. ${ }^{30}$

Outro elemento que se destaca a partir deste estudo é a dimensão de uma evangelização inculturada, que se torna viva na piedade mariana. Por meio de Guadalupe e Aparecida, e de tantos outros santuários marianos espalhados no território da América Latina, onde se venera a Mãe de Deus sob as mais diversas invocações, é possível perceber a riqueza da apreensão da presença, do papel e do lugar de Maria como expressão diferenciada da diversidade das culturas dos povos latino-americanos, que dão um colorido próprio à religiosidade popular na América Latina, apesar do crescimento do processo de secularização. ${ }^{31}$

Antonio González Dorado faz uma observação interessante em seu artigo: ele considera que as Conferências Gerais mostram a passagem da compreensão e apresentação de uma Maria conquistadora para uma Maria libertadora, demonstrando um novo momento evangelizador do Continente. ${ }^{32}$ É por isso que os Documentos das Conferências Gerais mostram a Mãe de Deus como uma mulher de fé viva, capaz de ser modelo de seguimento de Jesus Cristo, seu filho, e realizar o que a Igreja deve ser como tipo da Igreja (cf. Lumen Gentium, n. 63). Também capaz de mostrar o rosto de um Deus que ama a todos e os motiva para assumir o seu destino histórico, firmados no modelo deixado por Maria. O cântico do Magnificat (cf. Lc 1,46-55) retrata o espírito dos pobres de Javé, que, em sua confiança inabalável em Deus, aguardam a realização das promessas messiânicas. ${ }^{33}$ A pastoral da América Latina, especialmente a partir das Comunidades Eclesiais de Base (CEBs), foi o berço desse modo de considerar Maria.

Ela é modelo de mulher para as mulheres da América Latina. A Nova Evangelização deve ser promotora ativa da dignidade da mulher e promover o aprofundamento do papel da mulher na Igreja e na sociedade. Por isso, particularmente em Santo Domingo, os Bispos denunciam as violações da dignidade da mulher, especialmente as mais pobres, ${ }^{34}$ superando a sua

\footnotetext{
${ }^{30}$ Cf. PUEBLA, n. 895 e 937. particular a p. 3).

${ }^{33}$ Cf. PUEBLA, n. 297.

${ }^{34}$ Cf. SANTO DOMINGO, n. 105, 167 e 219.
}

${ }^{31}$ Cf. DOIG KLINGE, G. "Piedade popular". In: DOIG KLINGE, G. Diccionario Rio - Medellín - Puebla - Santo Domingo. São Paulo: Vida y Espiritualidad, 2007, p. 550.

${ }^{32}$ GONZÁLEZ DORADO, A. "De la Maria conquistadora a la Maria liberadora. Ensayo sobre Mariologia latino-americana”. Medellín, volume XII, n. 45 (marzo 1986), pp. 3-63 (de modo 
constatada inferioridade e condições em diversas circunstâncias da sociedade latino-americana. ${ }^{35}$

Maria é também modelo de serviço à evangelização que a Igreja do Continente é chamada a prestar a todos, de modo particular aos pobres e necessitados. Serva de Deus, ela se fez serva de todos, como está claro em sua visita à Isabel (cf. $L c$ 1,39-45).

\section{Referências bibliográficas}

ALBERIGO, G. "Fedeltà e criatività nella ricezione del Concilio Vaticano II. Criteri ermeneutici”. In: ALBERIGO, G. Transizione epocale. Studi sul Concilio Vaticano II. Bologna: Il Mulino, 2009.

CONCÍLIO ECUMÊNICO VATICANO II. Constituição dogmática Lumen Gentium, de 21 de novembro de 1964. In: ACTA APOSTOLICAE SEDIS 57 (1965), pp. 5-67.

CONSELHO EPISCOPAL LATINO-AMERICANO. "Rio de Janeiro (1955). $I^{a}$ Conferencia General del CELAM". Disponível em: <http://www. cpalsj.org/wp-content/uploads/2013/03/Documento_Conclusivo_Rio1. pdf $>$. Acesso em 27 de junho de 2017.

CONSELHO EPISCOPAL LATINO-AMERICANO. A Igreja na atual transformação da América Latina à luz do Concílio. Conclusões de Medellín. Petrópolis: Vozes, 1977.

CONFERENNCIA GERAL DO EPISCOPADO LATINO-AMERICANO. Puebla. A evangelização no presente e no futuro da América Latina. $3^{\mathrm{a}}$ Conferência. Petrópolis: Vozes, 1979.

CONSELHO EPISCOPAL LATINO-AMERICANO. Conclusões da IV Conferência do Episcopado Latino-Americano. Santo Domingo. Texto oficial. São Paulo: Paulinas, 1992.

CONSELHO EPISCOPAL LATINO-AMERICANO. Documento de Aparecida. Texto conclusivo da $V$ Conferência Geral do Episcopado Latino-Americano e do Caribe. Brasília e São Paulo: Edições da CNBB, Paulus e Paulinas, 2007.

${ }^{35}$ Cf. PUEBLA, n. 57. 
DENZINGER, H.; HÜENERMANN, P. Compêndio dos símbolos, definições e declarações de fé e moral. São Paulo: Paulinas e Loyola, 2007.

DOIG KLINGE, G. "Piedade popular”. In: DOIG KLINGE, G. Diccionario Rio - Medellín - Puebla - Santo Domingo. São Paulo: Vida y Espiritualidad, 2007, p. 550.

GONZÁLEZ DORADO, A. "De la Maria conquistadora a la Maria liberadora. Ensayo sobre Mariologia latino-americana". Medellín, volume XII, n. 45 (marzo 1986), pp. 3-63.

FASSINI MS, A. "Maria na pastoral latino-americana". Convergência 153 (1982), pp. 268-278.

GALILEA, S. "L'America Latina nelle conferenze di Medellín e Puebla. Um esempio di ricezione seletiva e creativa del concilio". In: ALEBERIGO G.; JOSSUA, J.-P. Il Vaticano II e la Chiesa. Brescia: Paideia, 1985, pp. 87-106.

IRMÃO NERY, FSC. Como vi e vivi Santo Domingo. Um diário. Petrópolis: Vozes, 1993.

MÜLLER, A. "La posizione e la cooperazione di Maria nell'evento di Cristo". In: FEINER, J.; LÖHRER, M. Mysterium Salutis. Nuovo corso di dogmatica come teologia dela storia dela salvezza. Vol. 6. Brescia: Queriniana, 1973, pp. 497-640.

PAPA BENTO XVI. Discurso na Sessão Inaugural dos trabalhos da V Conferência Geral do Episcopado da América Latina e do Caribe. In: ACTA APOSTOLICAE SEDIS 99 (2007), pp. 445-460.

PAPA JOÃO PAULO II. Carta Encíclica Redemptoris Mater, de 25 de março de 1987. In: ACTA APOSTOLICAE SEDIS 79 (1987), pp. 361-433.

PAPA JOÃO PAULO II. Carta Mulieris Dignitatem, de 15 de agosto de 1988. In: ACTA APOSTOLICAE SEDIS 80 (1988), pp. 1653-1729.

PAPA JOÃO PAULO II. Discurso no Santuário de Nossa Senhora de Zapopán. In: ACTA APOSTOLICAE SEDIS 71 (1979), pp. 227-231.

PAPA PAULO VI. Discurso de conclusão da terceira sessão do Concílio Ecumênico Vaticano II, em 21 de novembro de 1964. In: ACTA APOSTOLICAE SEDIS 56 (1964), pp. 1007-1018. 
PAPA PAULO VI. Exortação Apostólica Marialis Cultus, de 02 de fevereiro de 1974. In: ACTA APOSTOLICAE SEDIS 46 (1974), pp. 113-168.

PAPA PAULO VI. Exortação Apostólica Evangelii Nuntiandi, de 08 de dezembro de 1975. In: ACTA APOSTOLICAE SEDIS 68 (1975), pp. 5-76.

SCATENA, S. In populo pauperum. La Chiesa latino-americana dal Concilio a Medellín (1962-1968). Bologna: Il Mulino, 2007.

Geraldo Luiz Borges Hackmann

Doutor em Teologia pela Pontifícia Universidade Gregoriana (Roma) Professor no Curso de Teologia da Pontifícia Universidade Católica do Rio Grande do Sul Porto Alegre/RS - Brasil E-mail: gborgesh@pucrs.br 